\title{
Evaluation of Physiological Performance Parameters of Elite Karate-Kumite Athletes by the Simulated Karate Performance Test
}

\author{
Meryem Güler', Nusret Ramazanoglu ${ }^{2, *}$ \\ ${ }^{1}$ Institute of Health Sciences, Marmara University, Istanbul, Turkey \\ ${ }^{2}$ Faculty of Sports Sciences, Marmara University, Istanbul, Turkey
}

Copyright $\mathrm{O} 2018$ by authors, all rights reserved. Authors agree that this article remains permanently open access under the terms of the Creative Commons Attribution License 4.0 International License

\begin{abstract}
The purpose of this study was to evaluate physiological performance parameters of the elite karate-kumite athletes via the simulated karate performance test (SKPT). Sixteen elite male karate athletes from The Turkish National Team participated in the study(age: $23.31 \pm 4.27$ years, height: $173.4 \pm 4.91 \mathrm{~cm}$, weight: $68.8 \pm 8.17 \mathrm{~kg}$, BMI: $22.85 \pm 1.96 \mathrm{~kg} / \mathrm{cm}^{2}$ ). The SKPT protocol included 5 sets of 3 minutes simulated karate competition bouts, which included randomly timed 4 karate techniques ( 2 hands and 2 foot) in 7 seconds. With higher level of performance, the duration of the attacks increased whereas the rest periods shortened, but the total duration of the level remained constant ( 3 minutes). The blood lactate concentrations, heart rate, ventilation and oxygen consumption of the athletes were evaluated pre, mid and post SKPT. Statistically significant differences were found in all recorded parameters $(p<0.05)$. During the simulated test peak oxygen consumption values were 41,69 $\pm 4,82 \mathrm{ml} / \mathrm{kg} / \mathrm{min}$ at the $9^{\text {th }}$ minute. Whereas heart rate, ventilation and oxygen consumption decreased to warm up values at the end of recovery, blood lactate values remained elevated during the whole recovery period. In conclusion, the simulation protocol implemented in this study has been found to produce physiological strain similar to real competition and can be used for performance evaluation of elite karate athletes.
\end{abstract}

Keywords Karate, Performance Test, Lactate, Heart Rate, Oxygen Consumption

\section{Introduction}

Karate is one of the most popular martial arts which include defense and attack techniques against an opponent with a point-based performance outcome [1, 2, 3]. Karate movements contain sudden accelerations, directional changes, and sudden, fast and explosive attacks [4]. Karate athletes move very fast with short and narrow steps [5]. Maximal speed and explosive power are key elements of karate performance [6]. For the implemented techniques to possess point feature, they should be applied to eight regions of the body with features like good form, sporting attitude, vigorous awareness (zanshin), good timing and correct distance [3]. During the short and high intensity attacks, the necessary energy is supplied by the anaerobic system whereas during the low intensity movements and resting periods the aerobic system provides the necessary energy [7]. Therefore, training of the karate athletes has to integrate both anaerobic and aerobic components, which is usually performed as high intensity interval training [8]. In a championship, athletes have to participate in more than one competition in one day, which puts emphasis on recovery processes. $[9,10]$.

Recently, tests which simulate the physiological characteristics of karate were designed. The main purpose of those tests was examining the aerobic and anaerobic power of the athletes. Performance tests which were designed specific to karate simulated the techniques and application times of competitions. Generally, consecutive four attack techniques ( 2 punch and 2 kick) applied in 7 seconds with a rhythmic audio stimulant while recovery times decreased with time. Because the attack times maintained constant, total time of a set decreased with time. But in a competition, attacks are not implemented rhythmically and attack repetitions in a set vary. For those mentioned reasons, in the karate performance test protocol implemented in this study, attack-rest intervals were re-designed. In studies which included the design of a karate specific performance test, Chaabène et al (2012) used lactate concentrations and heart rate [11], and Nunan (2006) used ventilation (VE), oxygen consumption $\left(\mathrm{VO}_{2}\right)$ and heart rate for evaluating the physiological performance 
[12]. There weren't any study which investigates all these parameters together. The purpose of this study was to examine the blood lactate concentrations ( $\mathrm{La})$, ventilation (VE), oxygen consumption $\left(\mathrm{VO}_{2}\right)$ and heart rate $(\mathrm{HR})$ as performance parameters in the recovery processes at pre-, mid- and post-test during the designed simulated karate performance test (SKPT).

\section{Material \& Method}

\section{Participants}

Sixteen elite male karate athletes from the Turkish National Team participated in the study (age: $23.31 \pm 4.27$ years, height: $173.4 \pm 4.91 \mathrm{~cm}$, weight: $68.8 \pm 8.17 \mathrm{~kg}$, BMI: $\left.22.85 \pm 1.96 \mathrm{~kg} / \mathrm{cm}^{2}\right)$. Subjects were informed about the experimental protocol and risks, and signed an informed written consent before starting the test. The study protocol followed the declaration of Helsinki (1964) guidelines and was approved by the local ethics committee.

\section{Data Collection}

The blood lactate concentrations were analyzed by the Accutrend ${ }^{\circledR}$ Blood Lactate Analyzer (Roche, Germany). Blood samples were taken from the fingertip during all testing sessions. [13]. the index finger of the athletes was punctured and approximately 50 microliters (approximately 1 drop of blood) of the athlete's blood was taken for the measurement.

The expired gasses were analyzed by the ZAN 600 CPET (Nspire Health, Germany) spirometer metabolic gas measuring device, $\mathrm{VO}_{2}$ consumption and $\mathrm{VE}$ values evaluated. The HR of the athletes were measured and simultaneously computerized by putting a chest belt on the athlete with the Polar RS 800 (Finland).

The metronome software was displayed at the computer during the entire test in order to standardize the attack number and duration during the test.

\section{Simulated Karate Performance Test}

The SKPT included 5 sets of 3 minutes simulated karate competition bouts. The protocol was prepared according to the number of matches of the competitors in the European and World Championships. In each set, the number of attacks increased while the rest times decreased, and the attack times were left constant (Table 1). The loads were planned to be carried out with the stimuli that came randomly with 4 technical applications (2 hand and 2 foot techniques) in 7 seconds. During the test, the Kizami Zuki, Oi Mawashi Geri, Gyaku Zuki and Kizami Mawashi Geri techniques were implemented respectively. As soon as the athlete felt himself ready, the command system (metronome) was initiated, and with the first warning beep, the athlete started the test with 4 attacks to the sandbag. At the end of the attacks, the rest period started. The athlete was informed about the start of the next bout by a different warning beep as a reminder to get ready two seconds before 2 .

Table 1. SKPT protocol load, rest and set numbers

\begin{tabular}{llllll}
\hline Set & Cycles & $\begin{array}{l}\text { Attack Time } \\
(\mathrm{sec})\end{array}$ & $\begin{array}{l}\text { Rest } \\
(\mathrm{sec})\end{array}$ & $\begin{array}{l}\text { Time } \\
\begin{array}{l}\text { Total } \\
\text { Time } \\
(\mathrm{sec})\end{array}\end{array}$ \\
\hline 1. Set & 10 & 7 & 11 & $\begin{array}{l}3 \mathrm{~min} \\
(180 \mathrm{sec})\end{array}$ \\
\hline 2.Set & 12 & 7 & 8 & $\begin{array}{l}3 \mathrm{~min} \\
(180 \mathrm{sec})\end{array}$ \\
\hline 3. Set & 15 & 7 & 5 & $\begin{array}{l}3 \mathrm{~min} \\
(180 \mathrm{sec})\end{array}$ \\
\hline 4. Set & 18 & 7 & 3 & $\begin{array}{l}3 \mathrm{~min} \\
(180 \mathrm{sec})\end{array}$ \\
\hline 5. Set & 20 & 7 & 2 & $\begin{array}{l}3 \\
(180 \mathrm{sec})\end{array}$ \\
\hline
\end{tabular}

\section{Procedures}

All the subjects who participated in the study were tested on different days but in the same time periods. All the test measurements were completed at the Marmara University, Athlete Health and Research Center Laboratory. During the research, the laboratory conditions $\left(23^{\circ} \mathrm{C}\right)$ were tried to be kept approximately identical.

The athletes were informed about the test protocol, rules and requirements before the test. They were asked to eat at least 2 hours before the test on the test day, not to use stimulants like tea, coffee and medicine before the test, not to exercise 24 hours before the test and avoid challenging exercises on the test day. Moreover, they were asked to bring their own sports equipment that they use during competition (karate gi, gloves, stilts and tibia protectors). Adequate time was given to the athletes for familiarization to warning beeps and to the test protocol.

The analysis of the athletes' relaxed lactate concentrations were made during their 10-minute passive rest. Afterwards, the athletes warmed up for 15 minutes (5 min jogging, 5 min dynamic warm up, 3 min stretching and 2 min karate specific movements) before the SKPT. After the warm up, the second lactate analysis was carried out. The spirometer mask and the polar chest belt were put on the athlete during the test. During the exercise exhaled gasses and HR were measured at each $3^{\text {rd }}$ min during the test for 15 minutes and at each $2^{\text {nd }}$ min after the test during 5 minutes recovery. La measurements were taken in the middle of the test $\left(9^{\text {th }} \mathrm{min}\right)$, after the completion of the test $\left(15^{\text {th }} \min \right)$ and at each $2^{\text {nd }}$ min during the recovery phase. 


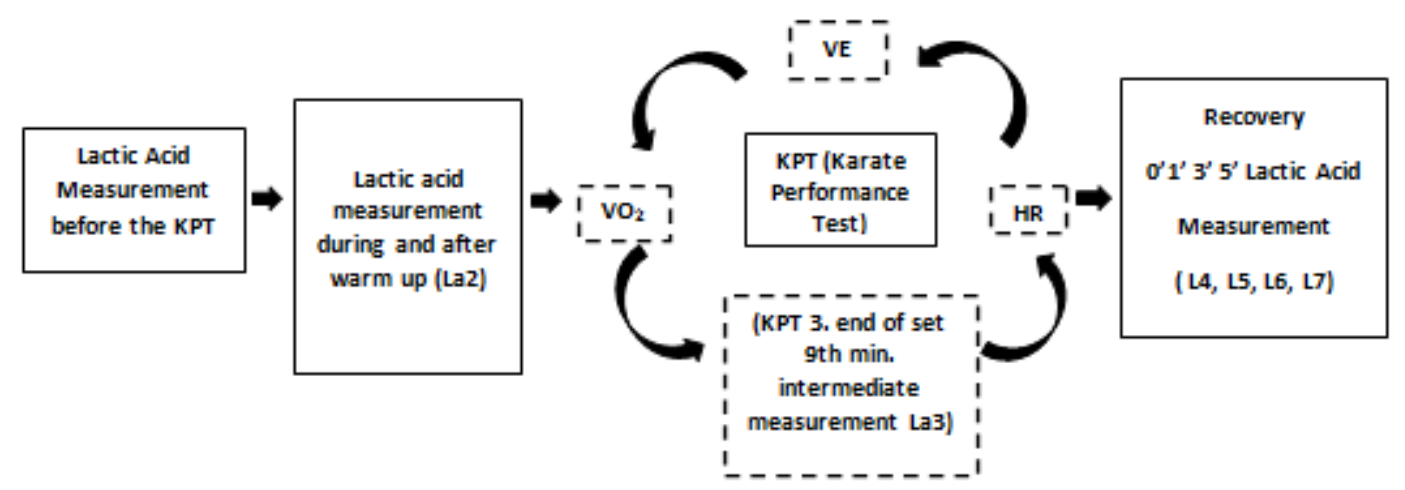

Figure 1. The Schematic Representation of the Procedure and Work Design

\section{Statistical Analysis}

The Nonparametric Friedman Test was performed to determine the significant differences in the physiological performance parameters between different data collection times. The level of significance was set at $P<0.05$.

\section{Results}

The averages and standard deviations of the lactic acid, ventilation, oxygen consumption and heart rate of the athletes are given in Table 2 for before, during and after the SKPT protocol.

Table 2. Descriptive information of SKPT

\begin{tabular}{|c|c|c|c|c|}
\hline & $\begin{array}{c}\mathrm{La} \\
\mathrm{mmol} / 1\end{array}$ & $\begin{array}{c}\mathrm{VO}_{2} \\
\mathrm{ml} \cdot \mathrm{min}^{-1} \cdot \mathrm{kg}^{-1}\end{array}$ & $\begin{array}{c}\mathrm{VE} \\
1 / \mathrm{min}\end{array}$ & $\begin{array}{c}\mathrm{HR} \\
\text { beats/min }\end{array}$ \\
\hline Rest & $2,27 \pm 0,48$ & - & - & - \\
\hline Warm Up & $2,50 \pm 0,68$ & - & - & - \\
\hline Start & - & $7,46 \pm 1,86$ & $14,88 \pm 3,667$ & $100,1 \pm 16,38$ \\
\hline After 3-min ( $1^{\text {st }}$ set $)$ & - & $33,66 \pm 5,70$ & $57,94 \pm 13,63$ & $158,8 \pm 15,80$ \\
\hline After 6-min $\left(2^{\text {nd }}\right.$ set $)$ & - & $39,46 \pm 5,58$ & $78,31 \pm 17,79$ & $173,6 \pm 14,14$ \\
\hline After 9-min $\quad\left(3^{\text {rd }}\right.$ set $)$ & $6,70 \pm 2,31$ & $41,69 \pm 4,82$ & $94,31 \pm 16,84$ & $182,1 \pm 12,31$ \\
\hline After 12-min $\quad\left(4^{\text {th }}\right.$ set $)$ & - & $41,46 \pm 4,57$ & $99,94 \pm 15,60$ & $184,3 \pm 10,48$ \\
\hline After 15 min- End $\left(5^{\text {th }}\right.$ set $)$ & $9,94 \pm 3,04$ & $40,91 \pm 6,63$ & $103,5 \pm 12,53$ & $187,4 \pm 10,00$ \\
\hline 1-min Rest & $9,97 \pm 3,32$ & $37,28 \pm 7,19$ & $83,81 \pm 13,49$ & $176,9 \pm 13,44$ \\
\hline 3-min Rest & $8,76 \pm 3,01$ & $13,39 \pm 3,50$ & $37,25 \pm 11,80$ & $123,6 \pm 13,31$ \\
\hline 5-min Rest & $8,47 \pm 3,41$ & $9,57 \pm 1,62$ & $24,06 \pm 6,516$ & $112,3 \pm 10,3$ \\
\hline
\end{tabular}

La; Lactic acid concentration; $\mathrm{VO}_{2}$; Oxygen consumption, VE; Ventilation, HR; Heart rate, SKPT; simulated Karate performance test

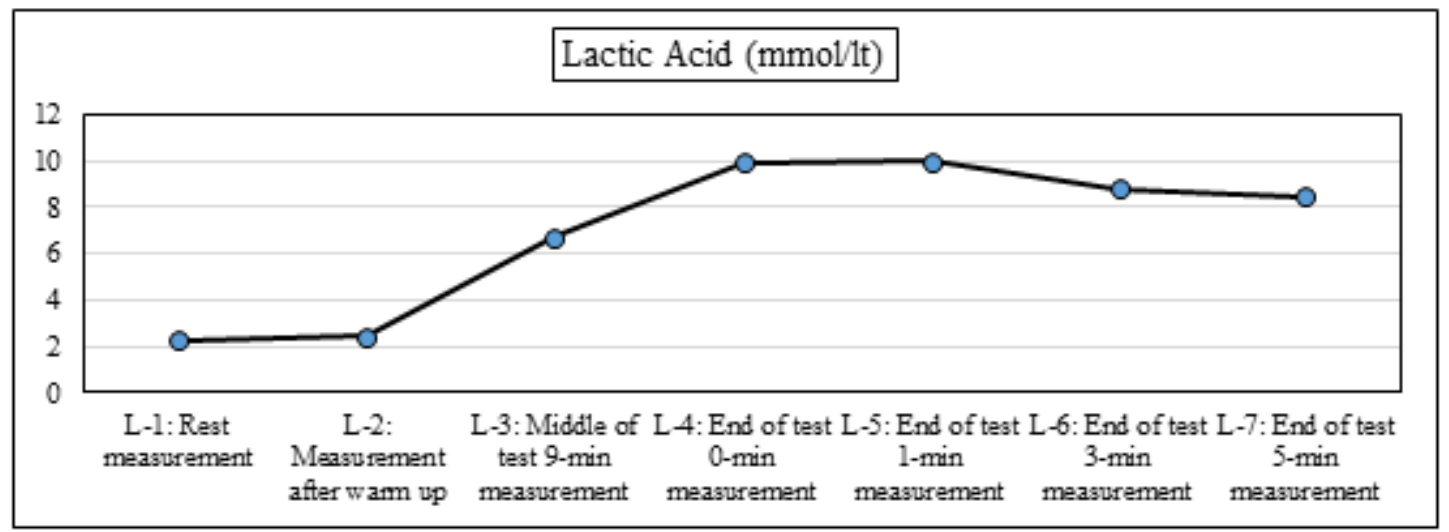

Figure 2. The lactic acid concentration values during the SKPT. 
A statistically significant difference was found in the blood lactate concentration levels before, during and after the simulated SKPT $(\mathrm{p}<0.05)$.

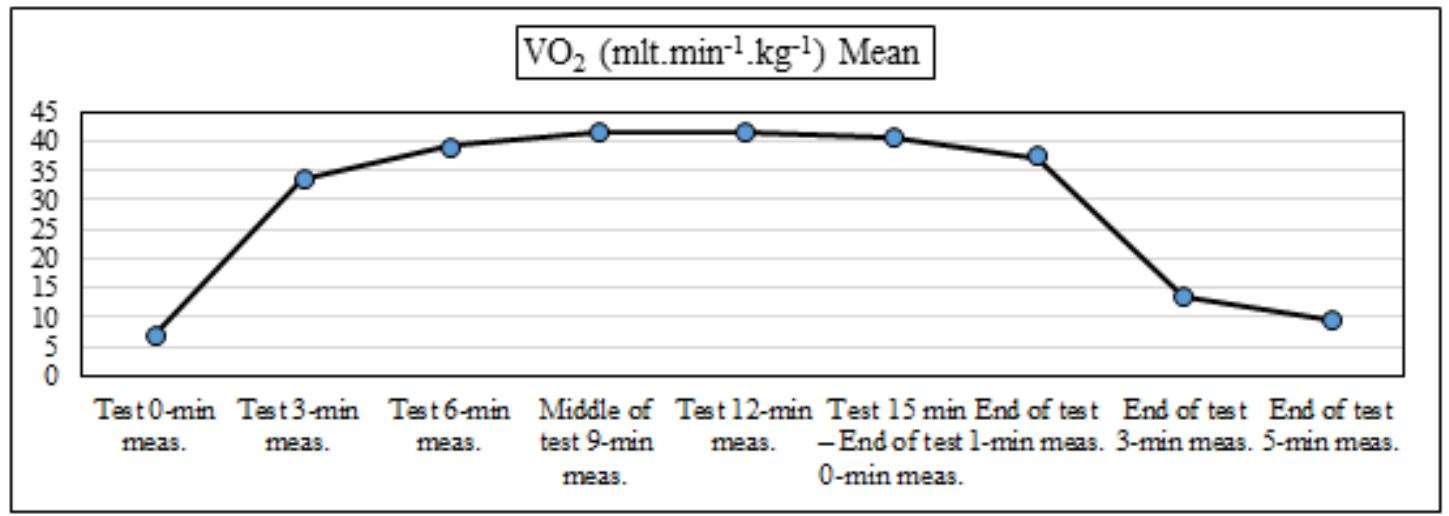

Figure 3. $\mathrm{VO}_{2}$ values during the SKPT.

A statistically significant difference was found between the $\mathrm{VO}_{2}\left(\mathrm{ml} \cdot \mathrm{min}^{-1} \cdot \mathrm{kg}^{-1}\right)$ average values of the athletes that were recorded during and after the SKPT $(\mathrm{p}<0.05)$.

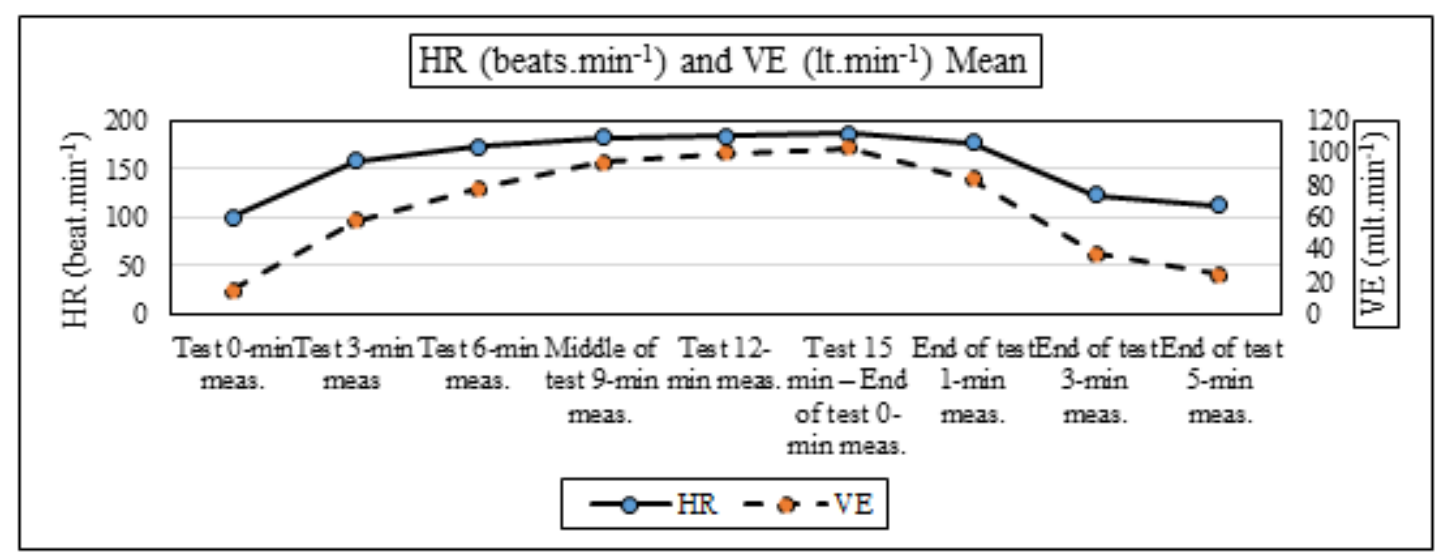

Figure 4. HR (heart rate) and VE (ventilation) values during the SKPT.

A statistically significant difference was found in the HR (beat. $\left.\mathrm{min}^{-1}\right)$ average values and VE $\left(1 . \mathrm{min}^{-1}\right)$ average values between pre and post SKPT $(\mathrm{p}<0.05)$.

\section{Discussion}

In this study, the physiological performance parameters of the athletes such as $\mathrm{VO}_{2}, \mathrm{HR}, \mathrm{VE}$ and La were evaluated using the simulated karate performance test (SKPT) that was designed particular to the conditions of karate. In the literature, a similar study exists in which the physiological parameters of karate athletes were examined by simulation of the competition performance $[11,12]$. The purpose of this study was to provide a more accurate protocol that incorporates attacks which occur based on the position during the competition together with randomly dispersed warning beeps for the attacks. The main purpose of this new designed protocol has been to create a simulation that will provide the intensity and feeling of the load during the competition.

The lactate values that emerged pre and post SKPT illustrate the oxygen deficits of the athletes. In order to be able to observe the fatigue levels of the athletes and to enable the determination of the load intensity in karate training programs, lactate measurement in the middle of the load was carried out. The blood lactate values increased with increasing exercise intensity, and significant changes were observed between pre-, mid- and post-SKPT measurement points. Zaborski et al (2015) examined the changes in the physiological processes of young karate athletes during their karate trainings and official competitions, and observed that the increase in their lactate values occurred immediately after the first fight and it was more or less stable with a slight increase in the subsequent fights [14]. They concluded that this result was close to the findings in other martial arts. In their studies, Tabben et.al (2013) presented that international karate contests create high lactate concentrations and cardiovascular responses that are close to the maximal values [15]. The examination of similar studies in the literature reveals that the lactate 
values found to be $10.8 \pm 2.6 \mathrm{mmol} \cdot \mathrm{l}^{-1}$ and $9.11 \pm 2.6$ $\mathrm{mmol} \cdot \mathrm{l}^{-1}[11,16]$. The lactate value of $9.12 \pm 2.59 \mathrm{mmol} \cdot \mathrm{l}^{-1}$ that was found in another study is quite close to the one in the present study [17]. The intensities of loads that have an impact on the athletes during SKPT are at a close level to each other, and this state can also be observed with regard to lactate values.

The fact that techniques like pushing and making the opponent fall by physical contact in judo competitions, demand power and related physical properties. This causes an increase in lactate values based on the repetition of anaerobic load [18]. When the Shuttle Run performance test [19] was applied to taekwondo - which is a similar martial art -, the lactate values were found to be higher than the ones measured in this study. In another martial art - kickboxing -, Ouergui et al (2014) found that lactate values were higher than the ones in the present study [10]. The lactate values were measured during the recovery process of the test procedure, in the third and fifth minutes. These differences between martial arts points out the fact that the competition structure and physiological needs are different from karate. In their study, Solberg and Borchsenius (2005) calculated the anaerobic threshold, and the lactate concentrations were recorded as $8.70 \pm 1.47$ $\mathrm{mmol} \cdot \mathrm{l}^{-1}$ in the treadmill test and $8.71 \pm 1.77 \mathrm{mmol} \cdot l^{-1}$ in the bicycle ergometer test [20]. As they indicated in their study, the lactate values that were attained as a result of the maximal load performed according to the Borg Scale reveal proximity with the values determined in the present study.

The HR values revealed changes in harmony with load and rest processes in the SKPT protocol. The studies in the literature exhibit a consensus regarding a substantial increase in HR during competitions in different martial arts $[10,19,21]$. In addition, Chaabene et al (2012a) reported that HR values increased parallel to lactate concentration. In their studies [11], Nunan (2006) and Chaabene et al (2012a) recorded HR values of $191 \pm 7 \mathrm{~min}^{-1}$ and 197.2 $\pm 7.5 \mathrm{~min}^{-1}$, respectively $[11,12]$. The values observed in the present study were lower than the values in literature. The reason for this may be the performance status of the subjects participating in this research as they were all elite athletes.

$\mathrm{VO}_{2}$ max is regarded as an indicator of the aerobic power of the athletes. Ravier et al (2004) utilized bicycle ergometer for the functional evaluations of karate athletes, and recorded the $\mathrm{VO}_{2}$ max averages of the whole group as $57.8 \pm 3.6 \mathrm{ml} \cdot \mathrm{min}^{-1} \cdot \mathrm{kg}^{-1}$ [8]. For comparison of aerobic field test results of karate athletes, researchers reported that the shuttle run test performed with the Tunisian taekwondo national team, the $\mathrm{VO}_{2} \max$ was $56.22 \pm 2.57 \mathrm{ml} \cdot \mathrm{min}^{-1} \cdot \mathrm{kg}^{-1}$ [20]. The values in this study were lower than the values in the studies of Ravier et al (2004) and Bouhlel et al (2006) $[8,21]$. The main reason for this difference may be due to the different protocol used in this study, which is designed particular to the conditions of karate competition. Nunan
(2006) and Tabben et.al (2014) used a similar protocol particularly designed for karate and their $\mathrm{VO}_{2} \max$ values were in the range $48.9 \pm 11.4 \mathrm{ml} \cdot \mathrm{min}^{-1} \cdot \mathrm{kg}^{-1}$ and $54.0 \pm 5.0$ $\mathrm{ml} \cdot \mathrm{min}^{-1} \cdot \mathrm{kg}^{-1}$, and the closest values to the ones in this study were observed $[12,15]$. The training conditions of the athletes who participated in this research directly affected these results. In the present study the interesting observation in this regard is the inability of the athletes to raise oxygen consumption after the $9^{\text {th }}$ minute. Either oxygen consumption has reached the maximum plateau level or as the remaining 6 minutes represent a very long period, local muscular fatigue doesn't allow to perform the attacking techniques with appropriate force output.

The ventilation values measured in the present study were lower than the previous studies on martial arts. Nunan (2006) as $130.6 \pm(16.0) 1 \cdot \mathrm{min}^{-1}$ and $127.8 \pm(14.4) 1 \cdot \mathrm{min}^{-1}$ [12]; Crisafulli et.al (2009) measured the VE values during a muay thai game simulation, and the VE values of the first, second and third rounds revealed lower VE values than the average as $90.5 \pm 8.31 \cdot \mathrm{min}^{-1}, 117.5 \pm 12.631 \cdot \mathrm{min}^{-1}$ and $110 \pm 8.431 \cdot \mathrm{min}^{-1}$ respectively [22]. The reason of this case may be the training conditions of the subjects who participated in the study.

$\mathrm{VO}_{2}$ max can play an important role in preventing fatigue during the trainings and fights, and developing recovery between consecutive fights [23]. According to Franchini et al (2009), active recreation provides the recovery of higher blood lactate in the $10^{\text {th }}$ and $15^{\text {th }}$ minutes as compared to passive recreation; according to Ouergui et al (2014), in the kickboxing tournaments, minimum 10 minutes' time can be allocated to the athlete to recover between consecutive matches [24]. Karate kumite competitions contain complicated skills, therefore tactical superiority is required. Karate is an art of sports that is performed with rapid plyometric phases; therefore the high lactate concentrations cause performance suppression. Karate trainings incorporate various intensities to load different energy systems, which could improve the ability to recover of athletes.

Consequently, the SKPT which was designed similar to the load-rest range in competitions, has a high usability as a performance test not only in karate but also in other martial arts such as taekwondo, judo and muay thai. We also believe that the SKPT is sufficient in determining the physiological state of the athlete in pre-, mid- and post-competition.

\section{Acknowledgements}

This study was supported by Marmara University grant BAPKO SAG-C-YLP-121214-0383 and produced from master's thesis. I would like to thank the employes of Marmara University Sports Science and Sports Health Research Center, Dr. Aytekin Soykan, Dr. H. Birol Çotuk, Dr. İrfan Gülmez, Dr. S. Orkun Pelvan, Assistant Nejla 
Gerçek and graduate student Taylan Balcıŏglu.

\section{REFERENCES}

[1] Imamura $\mathrm{H}$, Yoshimura $\mathrm{Y}$, Uchida $\mathrm{K}$, Nishimura $\mathrm{S}$, Nakazawa Anthony T. Maksimal Oxygen Uptake, Body Composition and Strength of Highly Competitive and Novice Karate Practitioners. Applied Human Science, 17(5):215-218, 1998.

[2] Filingeri D, Bianco A, Zangla D, Paoli A, Antonio P. Is karate effective in imporoving postural kontrol? Archives of Budo/Science of Martial Arts, 8(4):191-194, 2012.

[3] WKF (World Karate Federation); New Kata and Kumite Rules (version 9.0; online) Available from URL; http://www.wkf.net/pdf/competition_rules_version9_2015 _en1.pdf.: April, 2016).

[4] Soykan A, Ateş O, Güler M. 21 Yaş Altı Karate Elit Kata-Kumite Sporcularının Bacak Kuvveti ile Çabukluklarının Karşılaştırılması[Comparison of Leg Strength and Quickness of Under-21 Karate Elite Kata-Kumite Players]. Uluslararası Hakemli Akademik Sosyal Bilimler Dergisi[vİnternational Refereed Academic Social Science Journal], 1(01):96-100, 2011.

[5] Masciotra D, Ackermann E, Roth WM. "Maai": The Art of Distancing in Karate-Do Mutual Attunement in Close Encounters. Journal of Adult Education, 8(2), 119-132, 2001.

[6] Doria C, Veicteinas A, Limonta E, Maggioni MA. Energetics of karate (kata and kumite techniques) in top-level athletes. Eur J Appl Physiol, 107:603-610, 2009.

[7] Franchini E, Ouergui I, Chaabene H. Physiological Characteristics of Karate Athletes and Karate-Specific Tasks. Karate Kumite: How to Optimize Performance. Edit by Chaabene H. Published by OMICS Group eBooks, 2015.

[8] Ravier G, Grappe F, Rouillon JD. Application of force-velocity cycle ergometer test and vertical jump tests in the functional assessment of karate competitor. Journal of Sports Medicine and Physical Fitness, 44:349-355, 2004.

[9] Monedero J, Donne B. Effect of Recovery Interventions on Lactate Removal and Subsequent Performance. Int J Sports Med, 21:593-597, 2000.

[10] Ouergui I, Hammouda O, Chtourou H, Gmada N, Franchini E. Effects of Recovery Type after a Kickboxing Match on Blood Lactate and Performance in Anaerobic Tests. Asian J Sports Med, 5(2):99-107, 2014.

[11] Chaabène, H., Hachana, Y., Franchini, E., Mkaouer, B., Montassar, M., \& Chamari, K. (2012). Reliability and construct validity of the karate-specific aerobic test. The Journal of Strength \& Conditioning Research, 26(12), 3454-3460.
[12] Nunan, D. (2006). Development of a sports specific aerobic capacity test for karate-a pilot study. Journal of sports science \& medicine, 5(CSSI), 47.

[13] Forsyth, JJ, Farrally MR. A comparison of lactate concentration in plasma collected from the toe, ear, and fingertip after a simulated rowing exercise. British journal of sports medicine, 34 (1): 35-38, 2000.

[14] Zaborski B, Sakırı K, Dukanovıc N, Kostovskı Z. Changes in the Physiological Processes During Training and Official Competitions in Young Karate Athletes. Sports Science and Health, 5(2):105-110, 2015.

[15] Tabben M, Sioud R, Haddad M, Franchini E, Chaouachil A, Coquart J, Chaabane H, Chamaril K, Chollet CT. Physiological and Perceived Exertion Responses During International Karate Kumite Competition. Asian Journal of Sports Medicine, 4(4):263-271, 2013.

[16] Tabben M, Coquart J, Chaabene H, Franchini E, Chamari K, Tourny C. Validity and Reliability of New Field Aerobic Karate Specific Test (KST) for Karatekas. İnternational Journal of Sports Physiology and Performance, 9(6):953-958, 2014.

[17] Chaabène H, Hachana Y, Franchini E, Mkaouer B, Montassar M, Chamari K. Reliability and Construct Validity of the Karate-Specific Aerobic Test. Journal of Strength and Conditioning Research, 0(0):1-7, 2012.

[18] Guilherme AG, Desire Coelho F, Fabiana BB, Alessandra, CWG, Patricia B, Thomaz BA, Antonio HL. Relationship between Blood Lactate and Performance in a Specific Judo Test. Medicine and science in sports and exercise, 37(Supplement):S99, 2005.

[19] Bouhlel E, Jouini A, Gmada N, Nefzi A. Ben Abdallah K. Tabka Z. Heart rate and blood lactate responses during Taekwondo training and competition. Science Sports, 21(5):285-290, 2006.

[20] Solberg G, Borchsenius F. Respiratory Gas Exchange Indices for Estimating the Anaerobic Threshold. Journal of Sports Science and Medicine, 4:29-36, 2005.

[21] Campos FAD, Bertuzzi R, Dourado AC, Santos VGF, Franchini E. Energy demands in taekwondo athletes during combat simulation. European Journal of Applied Physiology, 112(4):1221-1228, 2012.

[22] Crisafulli A, Vitelli S, Cappai I, Milia R, Tocco F, Melis F, Concu A. Physiological responses and energy cost during a simulation of a Muay Thai boxing match. Applied Physiology, Nutrition, and Metabolism, 34(2), 143-150, 2009.

[23] Chaabène H, Hachana Y, Attia A, Mkaouer B, Chaabouni S, Chamari K. Physical and Physiological Profile of Elite Karate Athletes. Sports Medicine, 42(10): 829-843, 2012.

[24] Franchini E, de Moraes Bertuzzi RC, Takito MY, Kiss MA. Effects of recovery type after a judo match on blood lactate and performance in specific and non-specific judo tasks. Eur J Appl Physiol, 107:377-83, 2009. 